\section{Thalidomide as a Nitric Oxide Synthase Inhibitor and Its Structural Development}

\author{
Rumiko Shimazawa, ${ }^{*, 1)}$ Hiroko Sano, Aya Tanatani, \\ Hiroyuki MiYachi, and Yuichi Hashimoto
}

Institute of Molecular \& Cellular Biosciences, The University of Tokyo; 1-1-1 Yayoi, Bunkyo-ku, Tokyo 113-0032, Japan.

Received February 5, 2004; accepted March 8, 2004

Thalidomide has been found to exhibit weak nitric oxide synthase (NOS)-inhibitory activity. Structural development studies of thalidomide showed that some $\mathrm{N}$-2,6-dimethylphenylhomophthalimide analogs possess NOS-inhibiting activity.

Key words thalidomide; nitric oxide synthase (NOS); inhibitor; structural development

Thalidomide (1) is a hypnotic/sedative drug that was withdrawn from the market because of its severe teratogenicity. $^{2-4)}$ In spite of this, research into thalidomide was not halted, and the drug has since been established to be effective for the treatment of various diseases, including leprosy, myeloma and AIDS. ${ }^{3-5)}$ Although thalidomide affects production of various cytokines, the prevailing hypothesis was that the effectiveness of thalidomide in these diseases is elicited entirely through regulation of tumor necrosis factor (TNF)- $\alpha$ production.

We have been engaged in structural development studies of thalidomide, and have demonstrated that thalidomide is in fact a multi-target drug. Our studies resulted in the creation of TNF- $\alpha$ production regulators (including bi-directional ones, as well as pure inhibitors and enhancers), ${ }^{3,4,6-8)}$ androgen antagonists, ${ }^{3,4,9,10)}$ peptidase inhibitors, ${ }^{4,1-15)}$ glucosidase inhibitors, ${ }^{16,17)}$ thymidine phosphorylase inhibitors ${ }^{18)}$ and cyclooxygenase inhibitors. ${ }^{19,20)}$ Nevertheless, not all of the beneficial pharmacological effects elicited by thalidomide can be fully interpreted in terms of the above activities, indicating the existence of other target molecules/phenomena. We suspected that nitric oxide synthase (NOS) might be another target molecule of thalidomide, because the drug is effective against diabetes and has hypoglycemic effect, whereas NO acts as disease-progressing factor.

The family of nitric oxide synthases (NOS), which includes neuronal NOS (nNOS), endothelial NOS (eNOS) and inducible NOS (iNOS), ${ }^{21)}$ catalyzes the conversion of L-arginine to L-citrulline and nitric oxide (NO), an important cellular messenger molecule which has been implicated in both physiological and pathophysiological functions. In this paper, we describe evaluation of the NOS-inhibitory activity of thalidomide and its analogs.

First we investigated NOS-inhibitory activity of thalidomide (1). Inhibitory activity was assayed by monitoring nitrite/nitrate production using Ichimori's protocol with a little modifications. ${ }^{22,23)}$ Although the quantitative values differed from experiment to experiment, the results were basically reproducible, and average inhibition rate are presented in Table 1. In the assay system, the $\mathrm{IC}_{50}$ value of $N^{\mathrm{G}}$-nitro-L-arginine methyl ester (NNA, 2), which is a well-known analog of the endogenous NOS substrate, L-arginine, was determined to be $10 \mu \mathrm{M}$. The assay was performed in triplicate, and repeated at least three times. The result showed that thalidomide at $1 \mathrm{~mm}$ inhibits NOS by about 23\% (Table 1). Although the NOS-inhibitory activity of thalidomide was weak, one or more of the thalidomide metabolites or decomposition products might possess more potent activity. Such considerations led us to investigate the NOS-inhibitory activity of thalidomide-related compounds.

Thalidomide (1) is chemically labile and not suitable for a lead compound. So we chose $N$-phenyl(homo)phthalimide or $\mathrm{N}$-phenylquinazolinedione derivatives as lead compounds, based on our previous studies on peptidase inhibitors and COX inhibitors derived from thalidomide. ${ }^{4,12-16,19,20)}$ Substituted phthalimide and homophthalimide compounds were prepared by routine organic synthetic methods, i.e., condensation of appropriate amines with phthalic (3) or homophthalic anhydride (4-11). Quinazolinedione derivatives (12-14) were prepared by the condensation of 2,6-dialkylanilines and methyl anthranilate in the presence of triphosgene. ${ }^{15)}$ The 4-methoxy hemiacetal analog of 6 (15) was obtained quantitatively by the light-dependent autoxidation of 6 in methanol. ${ }^{12,25)}$ Compound $\mathbf{1 6}$ was prepared from the tricarbonyl analog, which was afforded by recrystallization of the hemiacetal (15) in water, by reaction of the carbonyl group at the benzyl position with (diethylamino)sulfur trifluoride. ${ }^{12,25)}$ The 2-dihydro derivative (17) was prepared by treatment of the amide, which was prepared by the acylation of 2,6-diethylaniline with 2-nitrobenzoyl chloride followed by reduction of the nitro group, with formalin and sodium hydroxide in ethanol, followed by treatment with triphosgene. ${ }^{15)}$ The 4dihydro analog (18) was prepared by treatment of 2-amino$N$-(2,6-diethylphenyl)benzenemethanamine, which was prepared from 2-nitrobenzyl bromide and 2,6-diethylaniline, with triphosgene. ${ }^{15)}$ The structures of all the compounds were confirmed by analysis data, and the analysis data were consistent with expectation.

Phthalimide derivatives with a five-membered ring, including compound 3, did not show apparent NOS-inhibitory activity in the concentration range examined. The ring expansion of the phthalimide moiety to a six-membered ring, i.e., homophthalimide derivatives (4-11), resulted in appearance of NOS-inhibitory activity, which was more potent than that of thalidomide (Table 1). $N$-Phenylhomophthalimide (4) at $1 \mathrm{~mm}$ inhibited NOS activity to the extent of about $42 \%$, and introduction of alkyl groups at the ortho-positions of the $\mathrm{N}$ phenyl substituent of 4 (compounds 5-9) enhanced the NOS-inhibitory activity (61-79\% inhibition). Although the most effective alkyl substituent could not be deduced from the investigated alkyl groups, the preferred site of substitution seems to be ortho. Quinazolinedione derivatives (1214), which are bioisosters of the corresponding homophthalimide derivatives $(5-9)$ in peptidase-inhibitory activity assays, ${ }^{15)}$ were unexpectedly inactive. Interestingly, reduction of the 3-carbonyl group (substituent $\mathrm{Y}$ in Table 1) of 13, i.e., compound $\mathbf{1 7}$, resulted in appearance of NOS-inhibitory ac-

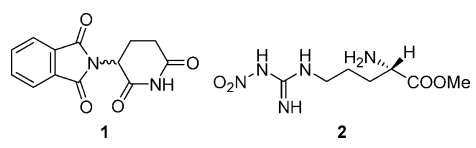

Fig. 1. Structures of Thalidomide (1) and $N^{\mathrm{G}}$-Nitro-L-arginine Methyl Ester (NNA: 2) 
Table 1. NOS-Inhibitory Activity of Compounds $\mathbf{1}-\mathbf{1 8}$

\begin{tabular}{|c|c|c|c|c|c|c|c|c|}
\hline \multirow{2}{*}{ Compound } & \multirow{2}{*}{$\mathrm{X}$} & \multirow{2}{*}{$\mathrm{Y}$} & \multirow{2}{*}{ Z } & \multirow{2}{*}{$\mathrm{R}_{1}$} & \multirow{2}{*}{$\mathrm{R}_{2}$} & & \multicolumn{2}{|c|}{ Inhibition rate } \\
\hline & & & & & & & $1 \mathrm{~mm}$ & $100 \mu \mathrm{M}$ \\
\hline 3 & $\mathrm{O}$ & $\mathrm{O}$ & - & $\mathrm{H}$ & $3^{\prime}-\mathrm{Me}$ & $5^{\prime}-\mathrm{Me}$ & $<10 \%$ & \\
\hline 4 & $\mathrm{O}$ & $\mathrm{O}$ & $\mathrm{CH}_{2}$ & $\mathrm{H}$ & $\mathrm{H}$ & $\mathrm{H}$ & $42 \pm 8 \%$ & $<10 \%$ \\
\hline 5 & $\mathrm{O}$ & $\mathrm{O}$ & $\mathrm{CH}_{2}^{2}$ & $\mathrm{H}$ & $2^{\prime}-\mathrm{Me}$ & $6^{\prime}-\mathrm{Me}$ & $66 \pm 18 \%$ & $63 \pm 10 \%$ \\
\hline 6 & $\mathrm{O}$ & $\mathrm{O}$ & $\mathrm{CH}_{2}$ & $\mathrm{H}$ & $2^{\prime}-\mathrm{Et}$ & $6^{\prime}-\mathrm{Et}$ & $64 \pm 5 \%$ & $31 \pm 5 \%$ \\
\hline 7 & $\mathrm{O}$ & $\mathrm{O}$ & $\mathrm{CH}_{2}^{2}$ & $\mathrm{H}$ & $2^{\prime}-\mathrm{iPr}$ & $6^{\prime}-\mathrm{iPr}$ & $(69 \pm 6 \%)^{a)}$ & $26 \pm 9 \%$ \\
\hline 8 & $\mathrm{O}$ & $\mathrm{O}$ & $\mathrm{CH}_{2}^{2}$ & $\mathrm{H}$ & $2^{\prime}-\mathrm{Me}$ & $6^{\prime}-\mathrm{Et}$ & $79 \pm 12 \%$ & $58 \pm 20 \%$ \\
\hline 9 & $\mathrm{O}$ & $\mathrm{O}$ & $\mathrm{CH}_{2}^{2}$ & $\mathrm{H}$ & $2^{\prime}-\mathrm{Me}$ & $6^{\prime}-\mathrm{iPr}$ & $61 \pm 17 \%$ & $25 \pm 2 \%$ \\
\hline 10 & $\mathrm{O}$ & $\mathrm{O}$ & $\mathrm{CH}_{2}$ & $\mathrm{H}$ & $2^{\prime}-\mathrm{Me}$ & $5^{\prime}-\mathrm{Me}$ & $44 \pm 14 \%$ & $17 \pm 6 \%$ \\
\hline 11 & $\mathrm{O}$ & $\mathrm{O}$ & $\mathrm{CH}_{2}$ & $\mathrm{H}$ & $3^{\prime}-\mathrm{Me}$ & $5^{\prime}-\mathrm{Me}$ & $31 \pm 17 \%$ & $<10 \%$ \\
\hline 12 & $\mathrm{O}$ & $\mathrm{O}$ & $\mathrm{NH}$ & $\mathrm{H}$ & $2^{\prime}-\mathrm{Me}$ & $6^{\prime}-\mathrm{Me}$ & $<10 \%$ & \\
\hline 13 & $\mathrm{O}$ & $\mathrm{O}$ & $\mathrm{NH}$ & $\mathrm{H}$ & $2^{\prime}-\mathrm{Et}$ & $6^{\prime}-\mathrm{Et}$ & $<10 \%$ & \\
\hline 14 & $\mathrm{O}$ & $\mathrm{O}$ & NH & $\mathrm{H}$ & $2^{\prime}-\mathrm{iPr}$ & $6^{\prime}-\mathrm{iPr}$ & $<10 \%$ & \\
\hline 15 & $\mathrm{O}$ & $\mathrm{O}$ & $\mathrm{C}(\mathrm{OH}) \mathrm{OMe}$ & $\mathrm{H}$ & $2^{\prime}-\mathrm{Et}$ & $6^{\prime}-\mathrm{Et}$ & $71 \pm 16 \%$ & $41 \pm 18 \%$ \\
\hline 16 & $\mathrm{O}$ & $\mathrm{O}$ & $\mathrm{CF}_{2}$ & $\mathrm{H}$ & $2^{\prime}-\mathrm{Et}$ & $6^{\prime}-\mathrm{Et}$ & $74 \pm 5 \%$ & $42 \pm 12 \%$ \\
\hline 17 & $\mathrm{O}$ & $\mathrm{H}_{2}$ & $\mathrm{NH}$ & $\mathrm{H}$ & $2^{\prime}-\mathrm{Et}$ & $6^{\prime}-\mathrm{Et}$ & $\left.(50 \pm 3 \%)^{a}\right)$ & $46 \pm 3 \%$ \\
\hline 18 & $\mathrm{H}_{2}$ & $\mathrm{O}^{2}$ & $\mathrm{NH}$ & $\mathrm{H}$ & $2^{\prime}-\mathrm{Et}$ & $6^{\prime}-\mathrm{Et}$ & $<10 \%$ & \\
\hline \multirow{2}{*}{\multicolumn{4}{|c|}{$\begin{array}{c}\text { Thalidomide (1) } \\
\text { NNA (2) }\end{array}$}} & & & & $23 \pm 8 \%$ & $<10 \%$ \\
\hline & & & & & & & $87 \pm 7 \%$ & $74 \pm 28 \%$ \\
\hline
\end{tabular}

a) Inhibitory activity of 7 and $\mathbf{1 7}$ was measured at $0.5 \mathrm{~mm}$ instead of $1 \mathrm{~mm}$, because these compounds showed poor solubility.

tivity, while reduction of another carbonyl group at position 1, i.e., compound $\mathbf{1 8}$, did not affect the activity. We cannot interpret these phenomena at this stage.

Chemically, homophthalimide derivatives are autoxidized at the benzylic methylene position in the tetrahydroisoquinoline ring to give a hemiacetal analog (15) in methanol or a tricarbonyl analog in water. ${ }^{12,24,25)}$ Therefore, $N$-phenylhomophthalimides (4-11) might inhibit the production from NO of nitrite/nitrate, which are the products measured directly by Ichimori's protocols, ${ }^{22,23)}$ through self-oxidization. However, the inhibitory activity of non-oxidizable analogs, i.e., the hemiacetal analog (15: already oxidized) and difluorinated analog (16: blocked at the benzylic position) is almost the same as that of the corresponding homophthalimide compound 6. This result suggests that $N$-phenylhomophthalimides (4-11) inhibit NOS directly, but do not merely inhibit production of nitrite/nitrate from NO.

In conclusion, we found firstly that thalidomide (1) has NOS-inhibitory activity, even though the activity is weak, and secondly, that some $N$-phenylhomophthalimide derivatives possess NOS-inhibitory activity which is more potent than that of thalidomide. Although the structure-activity relationships remain to be investigated, and the structure has not been optimized yet, the prepared compounds show moderate activity and represent a new class of non-amino-acidbased NOS inhibitors. Further structural development aiming at improvement of the NOS-inhibiting activity and at NOS isoform selectivity is in progress.

Acknowledgment The work described in this paper was partially supported by Grants-in-Aid for Scientific Research from The Ministry of Education, Culture, Sports, Science and Technology, Japan.

\section{References and Notes}

1) Present address: Pharmaceuticals and Medical Devices Evaluation Center, National Institute of Health Sciences; Toranomon 33rd Mori Bldg., 3-8-21 Toranomon, Minato-ku, Tokyo 105-8409 Japan.

2) Hales B. F., Nat. Med., 5, 489-490 (1999).

3) Hashimoto Y., Curr. Med. Chem., 5, 163-178 (1998).
4) Hashimoto Y., Bioorg. Med. Chem., 10, 461-479 (2002).

5) Calabrese L., Fleisher A. B., Am. J. Med., 108, 487-491 (2000).

6) Miyachi H., Azuma A., Ogasawara A, Uchimura E., Watanabe N., Kobayashi Y., Kato F., Kato M., Hashimoto Y., J. Med. Chem., 40, 2858-2865 (1997).

7) Miyachi H., Ogasawara A., Azuma A., Hashimoto Y., Bioorg. Med. Chem., 5, 2095-2102 (1997).

8) Shibata Y., Sasaki K., Hashimoto Y., Iwasaki S., Chem. Pharm. Bull., 44, 156-162 (1996).

9) Miyachi H., Azuma A., Kitamoto T., Hayashi K., Kato S., Koga M., Sato B., Hashimoto Y., Bioorg. Med. Chem. Lett., 7, 1483-1488 (1997).

10) Ishioka T., Kubo A., Koiso Y., Nagasawa K., Itai A., Hashimoto Y., Bioorg. Med. Chem., 10, 1555-1566 (2002).

11) Miyachi H., Kato M., Kato F., Hashimoto Y., J. Med. Chem., 41, 263-265 (1998).

12) Komoda M., Kakuta H., Takahashi H., Fujimoto Y., Kadoya S., Kato F., Hashimoto Y., Bioorg. Med. Chem., 9, 121-131 (2001).

13) Shimazawa R., Takayama H., Kato F., Kato M., Hashimoto Y., Bioorg. Med. Chem. Lett., 9, 559-562 (1999).

14) Shimazawa R., Takayama H., Fujimoto Y., Komoda M., Dodo K., Yamasaki R., Shirai R., Koiso Y., Miyata K., Kato F., Kato M., Miyachi H., Hashimoto Y., J. Enzyme Inhibit., 14, 259-275 (1999).

15) Kakuta H., Tanatani A., Nagasawa K., Hashimoto Y., Chem. Pharm. Bull., 51, 1273-1282 (2003).

16) Sou S., Mayumi S., Takahashi H., Yamasaki R., Kadoya S., Sodeoka M., Hashimoto Y., Bioorg. Med. Chem. Lett., 10, 1081-1084 (2000).

17) Takahishi H., Sou S., Yamasaki R., Sodeoka M., Hashimoto Y., Chem. Pharm. Bull., 48, 1494-1499 (2000).

18) Kita T., Takahashi H., Hashimoto Y., Biol. Pharm. Bull., 24, 860-862 (2001).

19) Noguchi T., Shimazawa R., Nagasawa K. Hashimoto Y., Bioorg. Med. Chem. Lett., 12, 1043-1046 (2002).

20) Suizu M., Muroya Y., Kakuta H., Kagechika H., Tanatani A., Nagasawa K., Hashimoto Y., Chem. Pharm. Bull., 51, 1098-1102 (2003).

21) Moncala S., Palmer R. M. J., Higgs E. A., Pharmacol. Rev., 43, 109142 (1991).

22) In this experiment, we used nNOS (Cayman, No. 60870).

23) Ichimori K., Stuehr D. J., Atkinson R. N., King S. B., J. Med. Chem., 42, 1842-1848 (1999).

24) Kakuta H., Takahashi H., Sou S., Kita T., Nagasawa K., Hashimoto Y., Recent Res. Devel. Medicinal Chem., 1, 187-211 (2001).

25) Takahashi H., Komoda M., Kakuta H., Hashimoto Y., Yakugaku Zasshi, 120, 909-921 (2000). 